\title{
O SISTEMA DE RANQUEAMENTO DO VOLEIBOL BRASILEIRO E SEUS DESDOBRAMENTOS
}

\author{
BRAZIL'S VOLLEYBALL RANKING SYSTEM AND ITS CONSEQUENCES
}

\section{EL SISTEMA DE RANKING DEL VOLEIBOL BRASILEÑO Y SUS IMPLICACIONES}

\author{
Marcelo Luis Ribeiro Silva Tavares*, Rafael Marques Garcia*, \\ Diego Ramos do Nascimento*, Carlos Henrique Vasconcellos Ribeiro", \\ Erik Giuseppe Barbosa Pereira*
}

\section{Palavras chave:}

Esportes.

Voleibol.

Classificação.

\begin{abstract}
Resumo: 0 objetivo deste artigo é analisar o sistema de ranqueamento do voleibol brasileiro e suas consequências na formação das equipes participantes. A metodologia é de natureza qualitativa, do tipo descritivo, utilizando como estratégia a análise documental. Os resultados exploram as justificativas para implantação do ranking dos atletas; o sistema de pontuação e suas consequências na composição das equipes; e as demandas recentes que têm feito a discussão ganhar contornos polêmicos. Concluise que o sistema vigente apresenta forte mecanismo restritivo na carreira de atletas nacionais e estrangeiros e somente com a constante atualização dos critérios atuais é que poderá se dinamizar os campeonatos nacionais formados por clubes e empresas dedicados ao esporte.
\end{abstract}

Keywords:

Sports.

Volleyball.

Ranking.

Palabras clave: Deportes.

Voleibol.

Clasificación.
Abstract: This article analyzes Brazilian volleyball's ranking system and its impacts on the make-up of participating teams. Its methodology is qualitative, descriptive, using documentary analysis as its strategy. The results explore the reasons for implementing the athlete ranking; the scoring system and its consequences on the make-up of teams; and the recent demands that made the discussion controversial. It concludes that the current system is strongly restrictive for Brazilian and foreign athletes' careers and only constant updating of the current criteria can dynamize Brazilian championships formed by clubs and companies dedicated to volleyball.

Resumen: El objetivo de este artículo es analizar el sistema de ranking del voleibol brasileño y sus consecuencias en la formación de los equipos. La metodología es de naturaleza cualitativa, del tipo descriptivo, utilizando como estrategia el análisis documental. Los resultados exploran las justificaciones para la implantación del ranking de los atletas; el sistema de puntuación y sus consecuencias en la composición de los equipos; y las demandas recientes que han hecho que la discusión gane contornos polémicos. Se concluye que el sistema vigente presenta un fuerte mecanismo restrictivo en la carrera de atletas nacionales y extranjeros y solo con la constante actualización de los criterios actuales será posible dinamizar los campeonatos nacionales formados por clubes y empresas dedicados al deporte.
*Universidade Federal do Rio de Janeiro. Rio de Janeiro, RJ, Brasil. E-mail: marcelostavares@globo.com; rafa.mgarcia@ hotmaill.com; personalnascimento@gmail.com; egiuseppe@eefd.ufr.j.br

**Fundação de Apoio à Escola Técnica. Rio de Janeiro, RJ, Brasil. E-mail: c.henriqueribeiro@gmail.com

Recebido em: 11-12-2018 Aprovado em: 03-06-2019 Publicado em: 27-10-2019

DOI: https://doi.org/10.22456/1982-8918.87657 (c) (i) () Licence 


\section{INTRODUÇÃOO}

A profissionalização esportiva é um fenômeno social estudado em diferentes campos (RODRIGUES; COSTA, 2014; RODRIGUES, 2002). Muito comum, o futebol é um esporte utilizado por cientistas sociais para explicar os mecanismos de aprendizagem, profissionalização e empregabilidade pelo qual passam inúmeros jovens (SOARES et al., 2011; DAMO, 2007; RIAL, 2006). Porém, ainda são raros os estudos sobre a profissionalização e o mercado de trabalho dentro de esportes que apesar de serem largamente conhecidos do grande público ficam distantes como temática de investigação acadêmica no que tange às escolhas profissionais. Compreendemos o voleibol como ambiente de trabalho especializado, em que 0 atleta tem de lidar com imposições sobre sua livre circulação entre clubes através de mecanismos norteadores do mercado e das qualificações técnicas de cada atleta.

Trazemos estudos sobre as questões da profissionalização e o mercado de trabalho, que no futebol já tem sido objeto de atenção, tal qual discorre Rodrigues (2002) acerca de como a seleção de talentos, a motivação e as expectativas de ascensão social impactam 0 investimento pessoal e familiar de muitos jovens no Brasil. Ressaltamos de antemão a necessidade de este tipo de estudo ser estendido para outras modalidades esportivas, uma vez que esses fatores se multiplicam e somam-se gradativamente em novos e variados contextos. Cada modalidade esportiva em sua dimensão competitiva é um nicho específico, um mercado de trabalho singular para atletas, técnicos, dirigentes e demais profissionais que se dedicam a esse ambiente. Há lacunas de conhecimento a serem preenchidas em investigações que explorem as complexidades de mercados de diferentes esportes e seus braços de institucionalização e profissionalização. Considerado por uma grande maioria como 0 segundo esporte nacional, o voleibol tem se desenvolvido ao longo das três últimas décadas a partir de um modelo de criação de equipes que, diferentemente da tradição centrada nos clubes recreativos, está fortemente relacionado ao patrocínio empresarial, que investe no esporte com vistas à visibilidade de suas marcas (NETTO et al., 2009; MEZZAROBA; PIRES, 2011; VLASTUIN; ALMEIDA; MARCHI JÚNIOR, 2008). Neste modelo, o patrocinador é 0 elo mais forte, pois é a partir da disponibilidade de seus recursos que são colocadas as estruturas físicas e humanas necessárias para a implementação de uma equipe esportiva. Infere-se que patrocinadores com mais recursos tendem a investir de forma abrangente para que suas equipes obtenham resultados, pelo menos proporcionais ao montante financeiro investido. Dentro de um campeonato nacional, o desequilibrio financeiro é notadamente visto nas equipes que podem contratar e outras que precisam ser mais contidas nesse aspecto, sobretudo na capacidade de gastos que precisam incluir despesas com deslocamento, estadias em hotéis e alimentação, por exemplo.

Trazemos neste estudo questões que relacionam o desenvolvimento deste esporte a partir de suas escolhas na estrutura organizacional, nas suas formas de controle e nos impactos deste mercado de trabalho. Reforçamos aqui o que Assumpção et al. (2010) compreende como um dos papéis da sociologia do esporte, que implica mostrar como as relações sociais são dadas pelo nível de desenvolvimento do sistema econômico. Para os autores

[...] as análises do esporte, ao considerar as relações sociais de poder de gênero, etnia e classe, não poderiam abrir mão de considerá-lo sob a lógica do capitalismo. A distribuição desigual de vantagens, de bens e de recursos, 
os incentivos, os patrocínios, os apoios são bastante diferenciados. A infraestrutura, os tipos de treinamento, o acesso ao material, os profissionais (médicos, fisioterapeutas, nutricionistas, psicólogos), as instalações seletivas, demonstram como a dinâmica segregacionista do capital se faz presente no universo esportivo e dependendo da modalidade em questão esta realidade fica mais evidente (ASSUMPÇÃO, et al., 2010, p. 95).

Neste desequilíbrio entre forças de mercado temos de singular neste esporte um mecanismo de controle nomeado "Ranking Oficial de Atletas" (ROA), instituído pela organização responsável com a anuência dos clubes envolvidos nesta competição. Este instrumento impede que jogadores de elevado nível técnico se concentrem em poucas equipes, independentemente da capacidade financeira dos seus gestores. Tal instrumento tem consequências para os profissionais envolvidos.

O sistema de ranqueamento do voleibol brasileiro foi instituído na temporada compreendida entre os anos de 1992/1993, com o objetivo de criar mecanismos de controle sobre 0 nível técnico das equipes masculinas e femininas nos campeonatos nacionais. Entretanto, houve consequências para o mercado de trabalho e restrições para a livre circulação de jogadores brasileiros e estrangeiros pelas equipes. Como exemplo adicional fora do voleibol, temos os casos das atletas de basquetebol Hortência e Paula, que foram proibidas de jogarem juntas no nível clubístico, por conta de uma imposição da Federação Paulista e da Confederação Nacional de basquete nas décadas de 1980 e 1990. Nossa lacuna investigativa se concentra na análise dos documentos do voleibol que implementam e restringem a formação das equipes no campeonato nacional das modalidades masculina e feminina.

O objetivo deste estudo consiste em analisar o sistema de ranqueamento do voleibol brasileiro e suas consequências na formação das equipes participantes.

Perguntamos: quais princípios balizam o documento "Ranking Oficial de Atletas" utilizado pela Confederação Brasileira de Voleibol?

\section{METODOLOGIA}

A metodologia deste estudo é qualitativa e utilizamos como estratégia a análise documental. A pesquisa qualitativa almeja amplificar possibilidades de análise ao compreender os fenômenos sociais, evitando assim condensá-los em categorias fixas e imutáveis (DEMO, 2012). Para Haguette (2007, p. 63), "os métodos qualitativos enfatizam as especificidades de um fenômeno e termos de suas origens e de sua razão de ser". Para o estudo qualitativo é, sobretudo, "[...] mister dar-Ihe credibilidade científica. É uma proposta necessária pelo simples fato de que fenômenos qualitativos precisam ser captados qualitativamente, sem perder de vista sua formalização implícita no campo do método científico" (DEMO, 2012, p.10).

Sobre a escolha pela estratégia da análise documental, o foco principal é extrair do documento suas informações vitais de modo a representá-lo mais compreensivamente aos leitores (RUIZ, 2011). Segundo Cellard (2008), esse processo se dá através de uma leitura preliminar que segue os seguintes passos: 1- contexto: busca-se entender em que contexto histórico e social o documento foi arquitetado e para quem é destinado; 2- autores e 
interesses: pretende-se conhecer a identidade, pretensões e consequências que motivaram a criação do documento pelos compositores; 3- confiabilidade: é possível assegurar-se das qualidades e informações transmitidas de modo a verificar a autenticidade da procedência do documento, certificando-se da relação entre compositores e sujeitos aos quais recai a escrita para evitar "abusos"; 4- natureza do texto: para averiguar se o contexto no qual foi escrito converge a quem se destina e, ainda, se apresenta simpatia ou antipatia por determinado grupo ; e 5- conceitos-chave do documento: para entender os termos empregados no documento em sua lógica interna atrelado ao seu objetivo principal.

Selecionamos dois documentos utilizados e disponibilizados pela Confederação Brasileira de Voleibol para o ranqueamento dos atletas na Superliga Nacional, desde as temporadas 2002/2003 até 2017/20181, a saber: Ranking Oficial de atletas feminino e masculino e o Texto Ranking Oficial da referida temporada ambos com 16 edições para cada naipe, contabilizando, assim, 64 versões do ROA 2 .

A cada temporada esses documentos são atualizados com a anuência dos clubes participantes da competição juntamente com a entidade máxima representante desse esporte no Brasil, a Confederação Brasileira de Voleibol (CBV). Assim, é possível obter no site oficial da entidade documentos relativos às temporadas anteriores sobre a mesma temática. A leitura dos documentos representa uma forma de compreensão de como vem se desenvolvendo um dos esportes mais populares no país, demonstrando uma sequência de avanços, recuos e aperfeiçoamentos de um modelo vigente há mais de 25 anos.

Para o tratamento dos dados, reportamo-nos à Análise de Conteúdo (AC), defendida e explorada por Bardin (2011). A autora afirma que a AC é um conglomerado de técnicas que se utiliza de procedimentos sistemáticos e descritivos de mensagens, categorizando-os em unidades de registro e análise. Nesse processo, destaca três etapas: a pré-análise, a descrição analítica e a interpretação referencial.

Na primeira, os dados coletados são submetidos a uma espécie de filtragem de acordo com a hipótese e objetivos do estudo, bem como o referencial teórico que subsidiará suas arguições, estabelecendo-se categorias de registro e análise; na segunda, o material é reorganizado em unidades e/ou blocos semânticos semelhantes, em que os autores iniciam um processo de aprofundamento das propostas de discussão; e na terceira, utilizam-se dados presentes na literatura para estabelecer inferências e tecer as discussões às quais o estudo se propõe conforme seus objetivos e parâmetros já preestabelecidos (BARDIN, 2011).

Reforçamos que a análise de conteúdo realizada neste estudo não prescinde da validade interpretativa, sendo esta capaz de ser avaliada e validada por outros pesquisadores, independentemente do tempo e contexto no qual foi gerada, possibilitando assim confiabilidade dos documentos analisados.

\section{RESULTADOS}

O voleibol é - assim como outros esportes - um campo social específico, em que pesem as inúmeras forças de ação realizadas por grupos distintos e com diferenças

1 Ressalta-se que, embora exista o ranqueamento desde 1992/1993, a CBV não dispõe esses documentos iniciais para consulta, ou seja, foram analisados apenas dezessete rankings. 
simbólicas para exercerem influência nos seus interesses, o que compõe o habitus de determinado grupo. Como Bourdieu (1983) afirma, os sujeitos agem a partir de construções intrínsecas na raiz de sua formação, portanto, é importante, por exemplo, que a análise de documentos oficiais que indiquem normas e posturas que balizem o campo de atuação dos sujeitos envolvidos em determinada atividade seja objeto de atenção de pesquisadores. Os documentos oficiais aos quais nos detemos são aqueles que norteiam a formação de equipes competitivas do voleibol e ocasionam permissividades/impasses na contratação e dispensa de atletas.

Em um ambiente esportivo com competições seguindo um calendário estável e regular, as regras para participação estão baseadas no fomento à formação de equipes com jogadores treinados para exercerem suas funções técnicas específicas, bem como no ajuste tático determinado pelo técnico. As contratações de jogadores no voleibol se baseiam, normalmente, nas necessidades técnicas específicas de cada equipe que está sendo formada. Assim, uma equipe não pode improvisar se precisa de um jogador para a posição de levantador, por exemplo. Ela precisa procurar nesse mercado de trabalho um profissional específico, capaz de exercer essa função.

Na medida em que há um sistema de controle por parte da entidade máxima desse esporte - com a anuência dos clubes participantes - que impede que os melhores jogadores do país venham a se concentrar em poucas ou até mesmo em uma única equipe, o ranking dos atletas se torna um elemento de restrição que precisa ser seriamente considerado pelas comissões técnicas de cada clube. Por outro lado, a principal justificativa para o ranking existir é salvaguardar a competitividade evitando que uma única equipe concentre os melhores atletas devido ao seu alto poder de investimento. Sem essas medidas de adequação, uma equipe poderia concentrar todos os atletas da seleção nacional ou até mesmo montar uma seleção formada por atletas estrangeiros de alta performance.

Em março de 2018 foi divulgado pela CBV que o ranking foi extinto na categoria masculina para a temporada 2018/2019, desta forma, nos detemos em analisar os documentos e o ranqueamento referentes ao período de 2002/2003 à temporada de 2017/2018 direcionados tanto à Superliga masculina quanto à Superliga feminina.

Ambos os documentos referentes aos textos do ROA tem construção básica formada por dois itens: a) Justificativa; b) Diretrizes.

\subsection{DA JUSTIFICATIVA DO ROA}

A literatura sobre voleibol o destaca como caso de sucesso em relação à tríade esporte, mídia e público (MARCHI JúNIOR, 2004; ANFILO, 2003). Ao longo das décadas de 1980, 1990 e de 2000, empresas foram associando suas marcas às equipes que iam sendo criadas e posteriormente desfeitas, em uma constante movimentação de atletas e comissões técnicas. Desde o ano de 1976 há competições nacionais nos naipes masculino e feminino. A partir da temporada compreendida entre os anos de 1994 e 1995 foi instituída a competição denominada de Superliga, nome que permanece até hoje.

Em meio a esse cenário, a CBV não mediu esforços para repatriar brasileiros que atuavam fora do país e distribuí-los pelas equipes nacionais, de forma que equilibrasse 
a competição ao não concentrar em uma ou duas equipes nomes de peso na época (principalmente os primeiros campeões olímpicos brasileiros, como Giovane Gávio, Alexandre Samuel - Tande -, Marcelo Negrão, entre outros). Dessa forma, ainda que de maneira incipiente, o órgão começava a balizar a composição das equipes com preceitos de equidade e igualdade entre os clubes participantes, o que seria o pontapé inicial para a criação do documento que hoje se denomina ROA.

Os textos relacionados à justificativa do documento que oficializa o ranking tinham a mesma disponibilidade de itens a partir de 2002/2003, sendo quatro itens no total. O primeiro é voltado para o objetivo do ROA de equilibrar tecnicamente as equipes, evitando que 0 poderio econômico influenciasse diretamente na competição. $O$ segundo item encoraja a inclusão dos atletas formados pelos clubes, beneficiando, assim, os clubes formadores. $O$ terceiro item também bonifica as equipes que contarem com atletas de idade elevada, sendo esta idade determinada ao início de cada edição da Superliga. Por fim, o quarto item incentiva a criação de novas equipes.

Em suas palavras finais, o documento reafirma que o modelo de ranqueamento é utilizado mundialmente com sucesso por outras modalidades, justificando assim sua consolidação no cenário esportivo e o compromisso da CBV em manter a excelência do voleibol nacional.

Algumas alterações ocorreram no texto para ambos os naipes. No feminino, o segundo item é excluído para a temporada 2007/2008 e suas considerações finais são suprimidas para a temporada 2014/2015. Já no masculino, o terceiro item é excluído para a temporada 2007/2008 e retorna para a temporada 2013/2014, além da retirada das considerações finais do texto para a temporada 2013/2014. Por fim, o documento referente à temporada 2017/2018 se resume a dois parágrafos para ambos os naipes ressaltando o objetivo do documento e seu tempo de utilização.

Para termos uma ideia, estamos falando de uma média de 12 equipes por temporada, tanto no masculino como no feminino.

\subsection{DAS DIRETRIZES DO ROA}

As diretrizes do ROA são compostas por uma série de itens que direcionam as indicações e pertinências para classificação e permissibilidade dos atletas nas equipes de acordo com pré-requisitos determinados. Esses balizamentos encontram-se destrinchados a seguir.

O primeiro deles refere-se aos critérios para atribuição de pontos para cada atleta. Segundo o documento, essa pontuação é pautada por "avaliações rigorosas e indicações dos clubes" seguindo métodos estatísticos e técnicos. Para a temporada 2002/2003 na Superliga Feminina foram ranqueadas 88 atletas brasileiras, número que foi crescendo temporada após temporada, chegando a 135 atletas brasileiras ranqueadas. Para a Superliga Masculina do mesmo ano, 143 atletas brasileiros foram ranqueados, contudo, nas temporadas seguintes, detecta-se uma oscilação no número de atletas, além da inclusão de estrangeiros (ver Tabela 1). 
Tabela 1 - Número de atletas ranqueados de acordo com período

\begin{tabular}{cccc}
\hline \multicolumn{4}{c}{ Atletas Ranqueados } \\
\hline Período & Número Total & Brasileiros & Estrangeiros \\
\hline $2003-2005$ & 143 & 143 & 0 \\
$2005-2006$ & 152 & 152 & 0 \\
$2006-2007$ & 140 & 140 & 0 \\
$2007-2008$ & 131 & 130 & 1 \\
$2008-2009$ & 127 & 126 & 1 \\
$2009-2010$ & 124 & $*$ & $*$ \\
$2010-2011$ & 129 & $*$ & $*$ \\
$2011-2012$ & 160 & $*$ & $*$ \\
$2012-2013$ & 135 & $*$ & $*$ \\
$2013-2014$ & 151 & $*$ & $*$ \\
$2014-2016$ & 171 & $*$ & $*$ \\
$2016-2017$ & 160 & $*$ & $*$ \\
$2017-2018$ & 172 & $*$ & $*$ \\
\hline
\end{tabular}

* Não há dissociação entre atletas brasileiros e estrangeiros

Fonte: Os autores, com base nos dados da Confederação Brasileira de Voleibol

A primeira alteração desse padrão ocorreu na Superliga Masculina na temporada 2014/2015, uma vez que somente os dez primeiros colocados do ano anterior fariam parte dos clubes votantes. Esta determinação passou a valer para a Superliga feminina na temporada seguinte. A segunda alteração ocorreu apenas para a Superliga Masculina no documento referente à 2017/2018, quando houve a inclusão do representante da Comissão dos Atletas na votação.

O item seguinte refere-se à pontuação distribuída para cada atleta ranqueado, variando de 1 a 7 , baseado nos critérios anteriormente informados. Inicialmente, para as duas Superligas (masculina e feminina) eram permitidos apenas dois atletas com 7 pontos por equipe segundo o item inscrição. Para a temporada 2007/2008 o texto foi modificado com a inclusão de um terceiro atleta de 7 pontos, desde que ele fosse repatriado. A partir da temporada 2012/2013, o número de atletas com 7 pontos passou para três por equipe. Atletas formados no clube de origem não pontuavam, independentemente do seu ranqueamento. A Superliga masculina manteve essas indicações nos demais textos, enquanto na Superliga feminina, para a temporada 2017/2018, houve o retorno para a limitação de duas atletas inscritas com 7 pontos. Para além dessas orientações, as equipes foram obrigadas a inscrever ao menos dois atletas menores de 22 anos e um deles deveria estar na súmula de cada partida. A questão da pontuação máxima do jogador (7) e a concentração desse jogador por equipe é uma preocupação constante desses documentos. Não nos cabe aqui inferir que jogadores de qualidade 7 - juntos em uma equipe - obrigatoriamente farão uma boa temporada a ponto de conseguirem levar suas equipes à conquista de campeonato em uma determinada temporada. Mas há de se ressaltar que a preocupação em não deixar que os de qualidade 7 migrem em grande maioria para uma única equipe é um dos pontos de balizamento para o ROA.

Algumas excepcionalidades contidas no item bonificação para atletas compuseram 0 documento. Para a Superliga feminina esse item informava que atletas abaixo de 17 anos não receberiam pontos, enquanto atletas acima de 33 anos receberiam um redutor a cada ano, até 
deixarem de ser pontuados. Essas informações sofreram a primeira alteração em 2013/2014, quando a idade máxima foi alterada para 36 anos, e a segunda alteração com a retirada da idade mínima a partir da temporada 2016/2017. Na Superliga masculina, a idade mínima iniciouse com 18 anos e foi alterada para 17 na temporada 2007/2008, sendo excluída do documento em 2014/2015. A idade máxima iniciou-se com 33 anos e se manteve no documento até a temporada 2006/2007, tendo seu retorno para os jogos de 2013/2014, com nova idade máxima alterada para 36 anos.

Em seguida a pontuação por equipe foi apresentada, com a pontuação máxima e mínima permitidas para participação de cada clube. A dinâmica de modificações da pontuação a cada temporada foi similar entre os dois naipes, conforme apresentado na tabela a seguir (Tabela 2).

Tabela 2 - Pontuação por equipe de acordo com o período

\begin{tabular}{ccccc}
\hline \multicolumn{4}{c}{ Pontuação por equipe } \\
\hline Masculino & \multicolumn{2}{c}{ Feminino } \\
\hline Período & Máximo & Mínimo & Máximo & Mínimo \\
\hline 2002 a 2011 & 32 & 0 & 32 & 0 \\
$2011-2013$ & 32 & 7 & 32 & 7 \\
$2013-2014$ & 32 & 0 & 32 & 0 \\
$2014-2017$ & 40 & 0 & 43 & 0 \\
$2017-2018$ & 40 & 5 & 43 & 0 \\
\hline
\end{tabular}

Fonte: Os autores, com base nos dados da Confederação Brasileira de Voleibol

O sistema de ranqueamento é, como um todo, um mecanismo de diferenciação dos atletas, porém, não apenas pela sua condição técnica, mas, sobretudo, pela diferenciação dos atletas brasileiros e estrangeiros. Assim, temos também duas categorias de atletas que são colocados de forma distinta através de pontos, apenas por serem brasileiros e outros por serem de outras nacionalidades. Essas categorias estão expostas nos itens atletas estrangeiros e retorno de atletas.

O número de atletas estrangeiros por equipe iniciou-se com um e passou para dois, mantendo-se assim até os dias atuais para as duas Superligas. Contudo, seu ranqueamento dependeria de alguns fatores, tendo sua pontuação zerada nos seguintes casos: a) se permanecesse na mesma equipe; b) se não tivesse participado da Superliga no ano anterior; $c$ ) se sua equipe se desligasse da competição; e d) caso o atleta fosse liberado pelo seu clube de origem. Quaisquer outras situações diferentes das listadas acima renderiam, automaticamente, 7 pontos ao atleta. Essas ordenanças se mantiveram até a temporada 2016/2017, com a seguinte alteração: 0 atleta estrangeiro seria ranqueado com 5 pontos a partir do primeiro ano.

O retorno de atletas objetivava reduzir a pontuação dos atletas brasileiros que atuavam no exterior para aumentar o nível de competitividade das Superligas. Na Superliga feminina, toda atleta que retornasse do exterior não era pontuada, independentemente da sua última pontuação no Brasil. Para a Superliga masculina, o padrão se dava numa redução gradual da sua pontuação de acordo com o número de anos que o atleta se manteve fora do país, com um redutor de 2 pontos para o primeiro ano e 1 ponto para cada ano sequencial. 
O item levantadoras(es) relatava que as equipes só poderiam escolher um atleta da posição de acordo com o listado pela CBV. Esse item se manteve no documento até a temporada 2007/2008 na Superliga masculina e até 2008/2009 na Superliga feminina.

O item ranking dizia respeito ao documento anexo que continha a pontuação determinada para os atletas. Os rankings da Superliga, tanto a masculina quanto a feminina, tiveram em média nove atletas ranqueadas com 7 pontos em cada edição de 2002/2003 a 2017/2018. Os atletas brasileiros que estivessem no exterior ou sem clube também eram ranqueados e compunham boa parte do grupo de 7 pontos, correspondendo a $65 \%$ de atletas desse grupo na temporada da Superliga masculina de 2003/2004, por exemplo. Para a Superliga feminina, esse panorama não mudou.

Os itens finais do documento eram compostos pelos assuntos gerais e nota oficial, destinados às informações gerais sobre o documento, além da assinatura do coordenador da CBV para cada temporada.

\section{ANÁLISE DOS RESULTADOS}

Após análise dos documentos referentes à formação do ranking no voleibol, verificase como a organização esportiva desse esporte e suas equipes afiliadas elegem o ranking de atletas como um dos pilares para a formação de equipes nos campeonatos nacionais. A diretriz principal do documento não deixa claro quais são os critérios de avaliação para ranqueamento de cada atleta. Como exemplo, há outros modelos de ranqueamento e recrutamento de atletas, tais como o Draft utilizado na Liga Nacional de Basquete Americana (NATIONAL BASKETBALL ASSOCIATION, 2018), que disponibiliza em seu site todos os requerimentos básicos, avaliações fisiológicas e demais regras de elegibilidade de cada atleta. A manutenção desse mecanismo parece estar perdendo força nos últimos tempos, a ponto de ter havido mudanças significativas no ranking feminino e a extinção do ranking no masculino para a edição da Superliga 2018/2019 (CBV, 2018)³.

O texto é claro sobre a necessidade de se conter o poder econômico, reforçando a justificativa de se manter o nível equilibrado entre as equipes, impondo restrições para a formação das equipes. Como visto em Assumpção et al. (2010), as diferenças econômicas estão postas e uma das possibilidades para a Sociologia do Esporte é a demonstração de como são resolvidos os problemas para igualar os desiguais: no caso do voleibol, as entidades que organizam os torneios nacionais dão caráter restritivo ao poderio econômico espelhado na criação e manutenção do ranqueamento por décadas seguidas, fazendo com que a livre circulação entre jogadores pelas equipes seja desestimulada.

Esse desestímulo acarreta mecanismos de restrição na composição de equipes esportivas, via qualificação por pontos. Será que este fato pode restringir momentaneamente e de forma enviesada a concentração de atletas? Além disso, será que esses efeitos tendem a limitar a capacidade do mercado de trabalho desse esporte ser expandido livremente, e ainda trazer limitações à vida profissional de dezenas de atletas de alto nível técnico? São perguntas ainda em aberto que o sistema de ranqueamento não equilibrou ao longo desses 25 anos de existência da Superliga.

3 Não houve justificativa para essa mudança, logo, especula-se que, talvez, essa medida se dê, entre outros fatores, à diferença no número de atletas no masculino (maior) e no feminino (menor). Assim, quanto maior o número de atletas em uma modalidade esportiva, e no caso categoria, maior a possibilidade de material humano disponível para recrutamento e treinamento, o que explicitaria a referida decisão. 
Ao colocarmos em questão a preocupação do documento com o retorno de atletas brasileiros que atuam no exterior visando ao equilíbrio competitivo das Superligas, emerge 0 que Maguire (2007) denomina de Atletas Repatriados. Com isso, inferimos a possível influência do ROA no fluxo migratório dos atletas brasileiros de voleibol, uma vez que atletas de outros esportes listam como motivos para escolha de sua praça esportiva o nível competitivo da Liga e de seu futuro clube (RIAL, 2008; DIMEO; RIBEIRO, 2009). Para além dessa política, devido ao limite de atletas com 7 pontos por equipe, a ida para o exterior parece ser uma ferramenta hábil para redução de pontuação sem que haja perda de desempenho.

Se compreendermos os resultados das Superligas como reflexo das circunstâncias e parâmetros restritivos dos rankings é consenso verificar que o complexo sistema de pontuação não determinou mais equilíbrio na competição, pois os campeonatos têm sido divididos pelos mesmos clubes ao longo dos anos, com mudança mínima de patrocinadores, mais da ordem do produto em evidência do que da empresa patrocinadora. O Quadro 1 apresenta as finais das Superligas masculina e feminina desde a temporada 2002-2003.

Quadro 1 - Equipes finalistas das Edições 2002-2003 até 2017-2018

\begin{tabular}{|c|c|c|}
\hline TEMPORADA & MASCULINO & FEMININO \\
\hline $2002-2003$ & Ulbra-RS X Unisul-SC & BCN Osasco X MRV Minas \\
\hline 2003-2004 & Unisul-SC X Ulbra-RS & Finasa Osasco X MRV Minas \\
\hline 2004-2005 & Banespa-SP X Telemig-MG) & Finasa Osasco X Rexona Ades-RJ \\
\hline $2005-2006$ & Cimed-SC X Telemig-MG & Rexona Ades-RJ X Finasa Osasco \\
\hline $2006-2007$ & Telemig-MG X Cimed-SC & Rexona Ades-RJ X Finasa Osasco \\
\hline 2007-2008 & Cimed-SC X Telemig-MG & Rexona Ades-RJ X Finasa Osasco \\
\hline 2008-2009 & Cimed Brasil Telecom-SC X Vivo-MG & Rexona Ades-RJ X Finasa Osasco \\
\hline $2009-2010$ & $\begin{array}{c}\text { Cimed Malwee-SC X Bonsucesso Montes } \\
\text { Claros-MG }\end{array}$ & Sollys Osasco X Unilever-RJ \\
\hline $2010-2011$ & SESI-SP X SADA Cruzeiro-MG & Unilever-RJ X Sollys Osasco \\
\hline 2011-2012 & SADA Cruzeiro-MG X Vôlei Futuro-SP & Sollys Nestlé-SP X Unilever-RJ \\
\hline $2012-2013$ & RJX-RJ X SADA Cruzeiro-MG & Unilever-RJ X Sollys Nestlé-SP \\
\hline 2013-14 & Cruzeiro-MG X Sesi-SP & Unilever-RJ X Sesi-SP \\
\hline 2014-15 & Cruzeiro-MG X Sesi-SP & Rexona-RJ X Molico Nestlé-SP \\
\hline $2015-16$ & Brasil Kirin-SP X Cruzeiro-MG & Rexona-RJ X Praia Clube-MG \\
\hline 2016-17 & Cruzeiro-MG X Taubaté-SP & Rexona-Sesc-RJ X Vôlei Nestlé-SP \\
\hline 2017-18 & Cruzeiro-MG X Sesi-SP & Sesc-RJ X Praia Clube-MG \\
\hline
\end{tabular}

Fonte: Os autores, com base nos dados da Confederação Brasileira de Voleibol (CBV $\left.{ }^{4}\right)$

4 Disponível em: http://superliga.cbv.com.br/historia-campeoes. Acesso em: 17 jun. 2018. 
Analisando todas as finais, desde a temporada 2002/2003 da Superliga Masculina verificamos que os mesmos clubes chegaram às finais em cinco temporadas, casos das equipes CIMED/SC e TELEMIG/MG. No caso do Cruzeiro/MG, esta equipe chegou a oito finais consecutivas em dezesseis temporadas analisadas.

Ao analisarmos a Superliga Feminina, verificamos uma hegemonia ainda mais antiga entre as equipes de Osasco/SP e Rio de Janeiro/RJ, ambas finalistas em 12 e 14 edições das 16 finais analisadas, respectivamente. Com isso, podemos novamente questionar o equilíbrio sugerido pelo ROA, que, mesmo funcionando há décadas, não impediu que apenas duas equipes se tornassem hegemônicas no voleibol feminino. Apesar de não existir uma relação direta, reforçamos que essas duas equipes tiveram ao longo do tempo maior número de jogadores com pontuação máxima, como, por exemplo, os números de Osasco/SP, com trinta e uma jogadoras ranqueadas com pontuação máxima e o Rio de Janeiro/RJ, com vinte e nove jogadoras nas mesmas condições, ao longo das 16 temporadas analisadas.

O ROA não necessariamente previne a hegemonia de certos clubes em termos de resultados esportivos, esse é o fato mais relevante a ser apresentado em nossa pesquisa. Se o objetivo da criação do ROA era não concentrar muitos bons jogadores em poucas equipes, possibilitando, com isso, mais equipes capazes de se alternarem na conquista de títulos nacionais ao longo dos anos, este não se concretizou, sobretudo na Superliga Feminina.

Já na Superliga Masculina, somente nas temporadas 2005/2006, 2006/2007 e 2009/2010 as equipes que chegaram às finais não tiveram nenhum jogador ranqueado com 7 pontos no seu elenco. Verificamos que neste período os jogadores de nível 7 estavam jogando no exterior, e a equipe Cimed, campeã da temporada 2005/2006 e vice-campeã na temporada seguinte, contou com jogadores novos e que posteriormente integraram a seleção brasileira. Ou seja, independentemente da restrição imposta pelo ROA, as equipes precisam criar estratégias para elevar o seu nível técnico sem ultrapassar o teto de pontos, entre elas estão a capacidade de revelar talentos desde as equipes de base e, ao longo das temporadas, manter um quadro permanente de jogadores.

No naipe masculino verifica-se uma diferença com relação ao feminino, uma vez que existem mais equipes alternando-se nas disputas pelos títulos e menos jogadores ranqueados com pontuação máxima compondo as equipes finalistas: onze jogadores ranqueados com sete pontos compuseram a equipe do Sada Cruzeiro/MG e sete jogadores compuseram a equipe do Minas Tênis Clube/MG, por exemplo.

Em relação ao naipe feminino, o ranking já está confirmado para a temporada 2019/2020, ao passo que no naipe masculino foi abolido desde a temporada 2018/2019, sem justificativa. Com relação à manutenção do ranking no naipe feminino apontamos a participação de Tifanny Abreu, primeira transexual a disputar este campeonato, pela equipe do Sesi/Bauru, desde a temporada 2017/2018: na edição 2018/2019, esta atleta passou a ser ranqueada com a pontuação máxima e para a próxima temporada, 2019/2020, manterá esta pontuação. Este tema da transexualidade no esporte é polêmico e foge da nossa presente investigação, mas cabe ressaltar a visão da CBV no que tange às políticas de inclusão e permanência no esporte de alto rendimento. Para o aprofundamento das questões relacionadas a esse tema, indicamos a leitura de Garcia e Pereira (2018). 
Ainda em relação ao naipe feminino, 0 anúncio da manutenção do ranking para a temporada 2019/2020 já provocou reflexos no mercado de transferência das atletas, uma vez que expoentes da modalidade, como Natália Zílio, Thaísa Daher, Gabi Guimarães e Fernanda Garay, já consideram a ideia de jogarem fora do Brasil, nas ligas turca e italiana, principalmente. Esse fenômeno reflete a incapacidade dos clubes que compõem a Superliga de absorver as atualizações provenientes do ROA.

\section{CONSIDERAÇÕES FINAIS}

A instituição do ranqueamento como norma para melhorar a distribuição de atletas com o intuito de não haver concentração de alto nível em uma mesma equipe e, assim, formar clubes muito fortes, não encontrou reverberação na realidade. Ao longo desses 25 anos de existência do ranqueamento verifica-se que algumas equipes conseguiram montar seus times valendo-se da norma, da pontuação máxima permitida e das liberalidades existentes em um documento que, modificado anualmente, manteve restrita a poucas equipes a capacidade de se manterem altamente competitivas e vencedoras.

Com o término do ranking na Superliga masculina brasileira, os atletas se tornaram livres para escolha de clubes, bem como as equipes estão aptas a buscarem os jogadores que gostariam de contratar. Este formato adotado agora pela CBV se assemelha ao de outras ligas emergentes da atualidade, como a polonesa, a italiana, a francesa, a russa ou mesmo a liga japonesa. Não temos como avaliar, contudo, se a lógica do livre mercado resolve o problema da hegemonia de poucas equipes frente às demais, mas era necessário um estudo sobre 0 ROA no voleibol brasileiro e suas consequências nos resultados das conquistas por equipes nesses mais de 25 anos, desde a sua criação.

A existência de atribuição de pontos às atletas na Superliga Feminina indica que esse é um tema ainda não esgotado. Com a nova composição das equipes, formadas pelo direcionamento do ranking, há chances de o sistema ser aperfeiçoado ou extinto, buscando novos parâmetros para estímulo aos patrocinadores e instituindo padrões de equilíbrio técnico mais adequados ao competitivo mercado de atletas deste esporte, que tanto atrai o público e a mídia.

Estudos futuros podem evidenciar que o sistema de ranqueamento precisa ser relacionado também à capacidade de investimento das equipes e as estratégias para incluir jogadores advindos das categorias de base para a equipe adulta. A lógica do livre mercado precisa evidenciar que a escolha e o bem-estar da atleta são elementos fundamentais em suas vidas, impactando suas trajetórias clubísticas e oportunidades de circulação entre os grandes centros. Por isso perguntamos: por que não repensar a manutenção do sistema de ranqueamento para o naipe feminino, conforme já foi feito com o naipe masculino?

\section{REFERÊNCIAS}

ANFILO, Milton Aparecido. A prática pedagógica do treinador da seleção brasileira masculina de voleibol: processo de evolução tática e técnica na categoria infanto-juvenil. Florianópolis, 2003. Dissertação (Mestrado em Educação Física) - Universidade Federal de Santa Catarina, 2003. 
ASSUMPÇÃO, Luís Otávio Teles; SAMPAIO, Tânia Mara Vieira; CAETANO, Juliana Naves Neves; CAETANO JÚNIOR, Marco Antônio; SILVA, Junior Vagner Pereira da. Temas e questões fundamentais na Sociologia do esporte. Revista Brasileira de Ciência e Movimento, v. 18, n. 2, p. 92-99, 2010.

BARDIN, Laurence. Análise de conteúdo. Lisboa: Edições 70, 2011.

BOURDIEU, Pierre. Questões de sociologia. Rio de Janeiro: Marco Zero, 1983.

CELLARD, André. A análise documental. In: POUPART, Jean et al. A pesquisa qualitativa: enfoques epistemológicos e metodológicos. Petrópolis: Vozes, 2008. p.295-316.

CBV. CONFEDERAÇÃO BRASILEIRA DE VOLEIBOL. Clubes definem pelo fim do ranking para a próxima temporada. 2018. Disponível em: http://2018.cbv.com.br/noticia/24744/clubesdefinem-pelo-fim-do-ranking-para-proxima-temporada. Acesso em: 17 jun. 2018.

DAMO, Arlei Sander. Do dom à profissão: uma etnografia do futebol de espetáculo a partir da formação de jogadores no Brasil e na França. São Paulo: Aderaldo \& Rothschild, 2007.

DEMO, Pedro. Pesquisa e informação qualitativa: aportes metodológicos. 5. ed. Campinas: Papirus, 2012.

DIMEO, Paul; RIBEIRO, Carlos Henrique Vasconcellos. 'I Am Not A Foreigner Anymore': A Micro-Sociological Study Of The Experiences Of Brazilian Futsal Players In European Leagues. Movimento, v. 15, n. 2, p. 33-44, 2009.

GARCIA, Rafael Marques; PEREIRA, Erik Giuseppe Barbosa. Ressignificações no esporte a partir da performance de Tifanny Abreu. E-Legis - Revista Eletrônica do Programa de PósGraduação da Câmara dos Deputados, v. 11, p. 24-44, nov. 2018.

HAGUETTE, Teresa Maria Frota. Metodologia qualitativa na sociologia. 11. ed. Petrópolis: Vozes, 2007.

MAGUIRE, Joseph. 'Política' o ‘Ética': deporte, globalización, migración y políticas nacionales. Revista Digital - Buenos Aires, Año 12, n. 111, ago. 2007. Disponível em: <https://www. efdeportes.com/efd111/deporte-globalizacion-migracion-y-politicas-nacionales.htm>

MARCHI JÚNIOR, Wanderley. "Sacando” o Voleibol. São Paulo: Hucitec; ljuí: Unijuí, 2004.

MEZZAROBA, Cristiano; PIRES, Giovani de Lorenzi. Breve panorama histórico do voleibol: do seu surgimento à espetacularização esportiva. Atividade Física, Lazer \& Qualidade De Vida: Revista de Educação Física, v. 2, n. 2, p. 3-19, maio 2011.

NATIONAL BASKETBALL ASSOCIATION. 2018 NBA Draft. Disponível em: http://www.nba.com/ draft\#/. Acesso em: 17 jun. 2018.

NETTO, Jacques Araújo; OLIVEIRA, Elzir Martins de; ABDALAD, Luciana Silva; CUNHA, Maria Auxiliadora Terra; SILVA, Carlos Alberto Figueiredo da. Análise SWOT: um estudo de caso com a elite do voleibol brasileiro. Fiep Bulletin, v. 85, p.419-426, jan. 2015.

RIAL, Carmen Silvia. Jogadores brasileiros na Espanha: emigrantes porém... Revista de Dialectología y Tradiciones Populares, v. 61, n. 2, p. 163-190, dec. 2006.

RIAL, Carmen Silvia. Rodar: a circulação dos jogadores de futebol brasileiros no exterior. Horizontes antropológicos, v. 14, n. 30, p. 21-65, dez. 2008. 
RODRIGUES, Francisco Xavier Freire. A sociologia das profissões e a sociologia do esporte: profissionalização e mercado de trabalho no futebol gaúcho. Caxambu: ANPOCS, 2002.

RODRIGUES, Francisco Xavier Freire; COSTA, Neuza Cristina Gomes da. O Futebol Americano em Mato Grosso: amadorismo ou profissionalismo? Coleção Pesquisa em Educação Física, v. 13, n. 4, p. 83-92, 2014.

RUIZ, João Álvaro. Metodologia científica: guia para eficiência nos estudos. 6. ed. São Paulo: Atlas, 2011.

SOARES, Antonio Jorge Gonçalves; MELO, Leonardo Bernardes Silva de; COSTA, Felipe Rodrigues da; BARTHOLO, Tiago Lisboa; BENTO, Jorge Olímpio. Jogadores de futebol no Brasil: mercado, formação de atletas e escola. Revista Brasileira de Ciências do Esporte, v. 33, n. 4, p. 905-921, dez. 2011.

VLASTUIN, Juliana Vlastuin; ALMEIDA, Bárbara Schausteck de; MARCHI JÚNIOR, Wanderley. O marketing esportivo na gestão do voleibol brasileiro: fragmentos teóricos referentes ao processo de espetacularização da modalidade. Revista Brasileira de Ciências do Esporte, v. 29, n. 3, p. 9-24, maio 2008. 